\title{
Sofosbuvir-based Regimens with Task Shifting Is Cost-effective in Expanding Hepatitis C Treatment Access in the United States
}

\author{
Channa R. Jayasekera*1,2, Rachel Beckerman ${ }^{3}$, Nathaniel Smith ${ }^{3}$, Ryan B. Perumpail ${ }^{1}$, \\ Robert J. Wong ${ }^{4}$, Zobair M. Younossi ${ }^{5,6}$ and Aijaz Ahmed ${ }^{1}$ \\ ${ }^{1}$ Liver Transplant Program, Division of Gastroenterology and Hepatology, Stanford University Medical Center, Stanford, \\ California, USA; ${ }^{2}$ Center for Innovation in Global Health, Stanford University, Stanford, California, USA; ${ }^{3}$ Maple Health Group, LLC, \\ New York, New York, USA; ${ }^{4}$ Division of Gastroenterology and Hepatology, Alameda Health System, Highland Hospital, Oakland, \\ California, USA; ${ }^{5}$ Department of Medicine, Center for Liver Diseases, Inova Fairfax Hospital, Falls Church, Virginia, USA; \\ ${ }^{6}$ Betty and Guy Beatty Center for Integrated Research, Inova Health System, Falls Church, Virginia, USA
}

\begin{abstract}
Background and Aims: The current paradigm of specialist physician-managed treatment of chronic hepatitis $\mathrm{C}$ virus infection (HCV) is inefficient in absorbing the approximately 3 million patients awaiting treatment in the United States. Task shifting-whereby specialist physicians screen patients for treatment eligibility but on-treatment monitoring is devolved to more abundant non-physician clinicians-achieves non-inferior treatment outcomes with second generation direct-acting antivirals ( $2^{\text {nd }}$ Gen DAAs), may increase treatment capacity, and may facilitate greater treatment access. We determined the cost effectiveness of $2^{\text {nd }}$ Gen DAAs with respect to interferon-based first-generation DAAs ( $1^{\text {st }}$ Gen DAAs) within a task-shifted treatment model. Methods: Using a previously described decision-analytic Markov structure, we modeled a hypothetical cohort of 1,000 patients with HCV genotype 1 infection over a lifetime horizon, based upon our outreach clinic's HCV treatment protocol. Treatmentnaïve and treatment-experienced HCV cohorts were modeled separately, based upon our outr8each clinic's demographics. Treatment response to $2^{\text {nd }}$ Gen DAAs was modeled based on our outreach clinic's data. Adverse events, utility, costing, and transition probabilities were sourced from the literature. Results: Driven by improved effectiveness and safety, as well as an expected increase in treatment capacity, $2^{\text {nd }}$ Gen DAAs treatment monitored by non-physician clinicians was projected to improve health outcomes and be dominant from a cost-effective perspective versus that of $1^{\text {st }}$ Gen DAAs. Trends were consistent across all assessed patient subpopulations. Conclusions: Based on an assumption of increased treatment capacity accompanying a task-shifted treatment model,
\end{abstract}

Keywords: Hepatitis C; Treatment access; Task shifting; Cost effectiveness. Abbreviations: HCV, hepatitis C virus; DAA, direct-acting antiviral; QALY, quality adjusted life year; PR, pegylated interferon with ribavirin; LVN, licensed vocational nurse; SVR12, sustained virologic response 12 weeks after end of treatment; SOF sofosbuvir; SMV, simeprevir; LDV, ledipasvir; HIV, human immunodeficiency virus; AASLD, American Association for the Study of Liver Diseases.

Received: 22 October 2016; Revised: 15 December 2016; Accepted: 03 January 2017 *Correspondence to: Channa R Jayasekera, Liver Transplant Program, Division of Gastroenterology and Hepatology, Stanford University Medical Center, Palo Alto, California 94304, USA. Tel: +1-650-725-3360, Fax: +1-650-498-5692, E-mail: crj@stanford.edu $2^{\text {nd }}$ Gen DAAs-based treatment was cost effective and cost saving as compared to $1^{\text {st }}$ Gen DAAs-based treatment for all $\mathrm{HCV}$ patient subgroups assessed.

Citation of this article: Jayasekera $C R$, Beckerman $\mathrm{R}$, Smith N, Perumpail RB, Wong RJ, Younossi ZM, et al. Sofosbuvir-based regimens with task shifting is cost-effective in expanding hepatitis $C$ treatment access in the United States. J Clin Transl Hepatol 2017;5(1):16-22. doi: 10.14218/JCTH.2016.00052.

\section{Introduction}

Chronic infection with hepatitis $\mathrm{C}$ virus (HCV) is estimated to affect over 3 million individuals, ${ }^{1,2}$ and an estimated $80 \%$ of these individuals remain untreated. ${ }^{3}$ Low treatment rates have been attributed to under-diagnosis of HCV-with approximately $50 \%$ of chronically-infected individuals unaware of their disease-and to the adverse effect-prone interferonbased treatment options which have represented the standard of care until recently. ${ }^{4}$ Along with the recent guidelines from the Centers for Disease Control and Prevention that aim to expand HCV screening, highly effective and safe second generation direct-acting antivirals ( $2^{\text {nd }}$ Gen DAAs) have the potential to close this treatment gap. ${ }^{5}$

While drug acquisition costs of $2^{\text {nd }}$ Gen DAAs-based treatment may be a barrier to treatment access, the high effectiveness, short treatment durations, and safety of these agents bestow considerable overall cost effectiveness for treating HCV genotype 1 , at levels remarkably less than a cost-effectiveness threshold of $\$ 50,000$ per quality adjusted life year (QALY) gained, even in difficult-to-treat subpopulations. ${ }^{6-9}$ Moreover, as more competing DAA regimens enter the market, drug cost as a proportion of treatment-related costs is likely to decline.

A less-addressed challenge to treatment access is the limited workforce available to deliver care to approximately 3 million HCV-infected patients in the United States. HCV treatment remains dominated by gastroenterologists, hepatologists, and infectious diseases specialists, who represent a workforce of approximately 19,000 and are typically located in urban referral medical centers. ${ }^{10}$ Even when patients and specialists are geographically nearby, the proportion of patients linked to care is low. Indeed, recent data from 
Philadelphia County-a large urban center with a high concentration of medical specialists-demonstrate that only $6 \%$ of the estimated HCV-infected population was under regular care and that only $3 \%$ received treatment. ${ }^{11}$ Patients in medically underserved areas, where $20 \%$ of the United States' population resides, therefore, appear even more likely to remain outside the continuum of HCV care. ${ }^{12}$

Channeling patients from rural communities to specialist clinics in urban referral centers is impractical and inconvenient. An alternative strategy is to empower a more abundant and accessible local cadre of non-physician (mid-level) healthcare providers to deliver HCV care-a concept known as task shifting. ${ }^{13}$ The viability of such programs at-scale is buttressed by the safety, effectiveness, and simplicity of interferon-free $2^{\text {nd }}$ Gen DAAs (i.e. elbasvir+grazoprevir, ledipasvir+sofosbuvir (LDV/SOF), ombitasvir+paritaprevir +ritonavir, and dasabuvir, sofosbuvir+simeprevir (SOF+SMV)). We previously demonstrated that devolution of $2^{\text {nd }}$ Gen DAAs-based HCV treatment to appropriately supervised, non-physician healthcare providers at outreach clinics in medically underserved areas in California achieved rates of treatment adherence, safety, and effectiveness that were comparable to those seen in pivotal clinical trials and to 'real world' experiences reported from tertiary medical centers. ${ }^{14}$

Task shifting models in medically underserved areas could, therefore, be instrumental to improving HCV treatment access in the United States. However, the scaling up of such models necessitates a better understanding of the budgetary impact and cost effectiveness of $2^{\text {nd }}$ gen DAAs regimens vis-à-vis first generation DAAs-based treatment $\left(1^{\text {st }}\right.$ Gen DAAs; e.g. pegylated interferon+ribavirin (PR) with boceprevir, simeprevir, or telaprevir). In this analysis, we determined the budgetary impact and cost-effectiveness of $2^{\text {nd }}$ Gen DAAs-based treatment, across different treatment capacity scenarios as facilitated by task shifting, and compared to $1^{\text {st }}$ Gen DAAs-based treatment.

\section{Methods}

\section{Medically underserved areas}

'Medically underserved area' is an official designation of the Health Resources and Services Administration of the United States Department of Health and Human Services. They are defined as geographic tracts that fall below a threshold of the Index of Medical Underservice-an index incorporating the ratio of primary medical care physicians per 1,000 population, infant mortality rate, and percentage of the population aged 65 years or over.

\section{Task shifting in outreach clinic treatment}

We operate three hepatology outreach clinics in medically underserved areas located 181 to 236 miles from our academic medical center. Our task-shifted treatment model, in contrast to the conventional treatment model involving frequent direct contact between the specialist physician and the patient, was instituted after our favorable experience that yielded very low rates of drug intolerance or adverse events with $2^{\text {nd }}$ Gen DAAs.

In our treatment model, patients with $\mathrm{HCV}$ were evaluated in outreach clinics at least 3 days a month during a full-day hepatology clinic conducted by a hepatologist from our academic medical center. In patients prescribed $2^{\text {nd }}$ Gen
DAAs, routine follow-up was performed via telephone calls conducted by an experienced, part-time licensed vocational nurse (LVN) and the LVN's support staff of medical assistants, through which medication adherence, tolerance, adverse events, and timely routine laboratory testing were assessed. Laboratory results and adverse effects reported by the patients were remotely reviewed by the hepatologist, within 24 hours and through an electronic health record. On-call hepatology fellows and/or hepatologists were paged immediately with critical laboratory results and symptoms deemed urgent by the patients. In addition, chart checks were performed up to 5 times per month to review treatment tolerance and safety. Patients with persistent issues were scheduled for urgent clinical follow-up by the hepatologist on a case-bycase basis. The hepatologist and LVN remained available to patients by telephone and secure messaging though the electronic health record system, and could be scheduled for nonroutine visits at the next clinic date or referred to local urgent care facilities for more pressing concerns. Patients requiring a higher level of care were afforded the option of being transferred to our academic medical center.

The hepatologist assessed all patients at the outreach clinic at approximately 12 weeks after completion of therapy, in order to determine achievement of viral clearance, which was defined as undetectable HCV RNA 12 weeks after end of treatment (sustained virologic response-12; SVR12).

\section{Budgetary impact and cost-effectiveness modeling}

Using a previously described decision-analytic Markov structure, we modeled a hypothetical cohort of 1,000 patients infected with HCV genotype 1 over a lifetime horizon based upon our outreach clinic's HCV treatment protocol. ${ }^{8}$ We also modeled independent cohorts of treatment-naïve and treatment-experienced HCV genotype 1 patients from a US third-party payer perspective over a lifetime horizon.

Mirroring our outreach clinic's demographics, the population modeled consisted of $11.7 \%$ treatment-naïve noncirrhotic patients, $14.8 \%$ treatment-naïve cirrhotic patients, $32.4 \%$ treatment-experienced non-cirrhotic patients, and $41.1 \%$ treatment-experienced cirrhotic patients (Fig. 1). The average age was 62 years. The outcomes and costs were discounted at an annual rate of $3.0 \%$, in accordance with Academy of Managed Care Pharmacy guidelines. ${ }^{15}$

Patients were modeled to receive treatment with either PR $+1^{\text {st }}$ Gen DAAs or an interferon-free $2^{\text {nd }}$ Gen DAAs regimen. SVR1 2 rates for $1^{\text {st }}$ Gen DAAs were taken from published realworld treatment outcome data for boceprevir+PR. ${ }^{16}$ SVR12 rates for $2^{\text {nd }}$ Gen DAAs were obtained from our experience in outreach clinics, published previously. ${ }^{14} 1^{\text {st }}$ Gen DAAs were modeled as a class, with effectiveness and drug acquisition costs assumed to be equivalent for both boceprevir- and telaprevir-containing regimens. $2^{\text {nd }}$ Gen DAAs were also modeled as a class, with effectiveness inputs assumed equal to SOF+SMV, which was the only $2^{\text {nd }}$ Gen DAA with sufficient data collected in our clinic at time of analysis. Drug wholesale acquisition costs for $2^{\text {nd }}$ Gen DAAs were assumed equivalent to LDV+SOF for 12 weeks, given that patients in our setting were no longer typically prescribed the more expensive SOF+SMV regimen.

Given shorter treatment courses and fewer laboratory monitoring requirements, treatment with $2^{\text {nd }}$ Gen DAAs was conservatively assumed to double treatment capacity-a phenomenon we have already experienced at our outreach clinics 


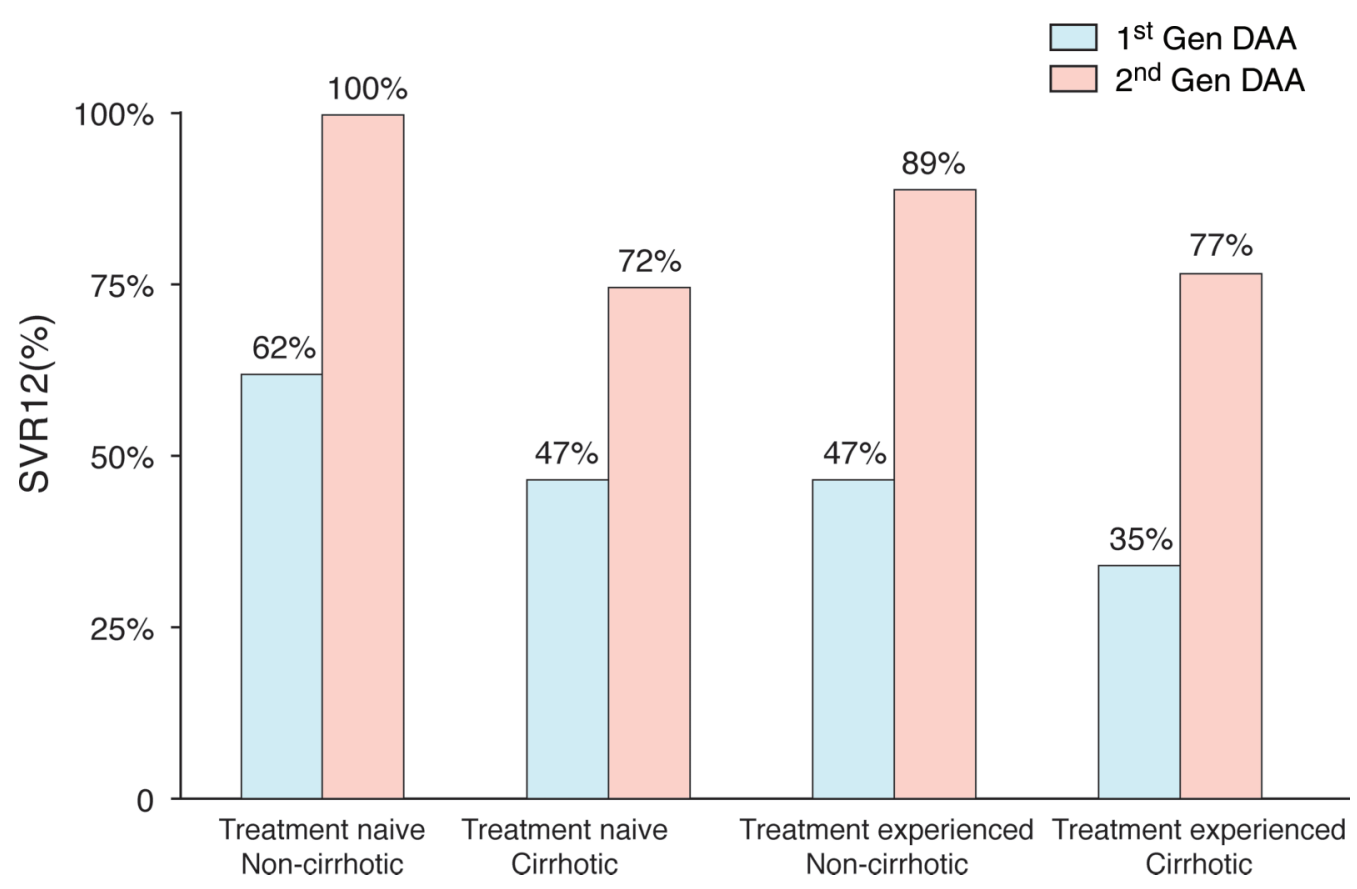

Fig. 1. Patient clinical characteristics inputs and sustained virologic response rates. SVR 12 , sustained virologic response 12 weeks after end of treatment; $1^{\text {st }}$ Gen DAA, first generation direct-acting antiviral agents; $2^{\text {nd }}$ Gen DAA, second generation direct-acting antiviral agents. Analysis only includes patients with hepatitis $C$ genotype 1 .

and demonstrated in other resource-limited settings with human immunodeficiency virus (HIV) infection patients. ${ }^{14,17}$ Hence, the model consisted of 1,000 patients receiving $2^{\text {nd }}$ Gen DAAs in the intervention arm, and in the comparator arm, 500 patients receiving $P R+1^{\text {st }}$ Gen DAAs and 500 patients remaining untreated.

We based healthcare utilization of $2^{\text {nd }}$ Gen DAAs on American Association for the Study of Liver Diseases and Infectious Diseases Society of America (AASLD) guidelines, current practice in our clinics, and hepatologist consensus (Table 1 ). ${ }^{18}$ For $1^{\text {st }}$ Gen DAAs, we used the monitoring paradigm recommended at the time by AASLD (accessed July, 2014). ${ }^{8}$ For the model's base case, it was assumed that the LVN reimbursement rate for routine follow-up evaluation was incident to physician services (i.e. under the physician's Provider Identification Number) and, therefore, billed identically to the physician reimbursement rate. Transition probabilities, utilities, and cost estimates (in 2014 USD) were based on literature and hepatologist consensus, as described previously. $^{8}$

A first sensitivity analysis assumed that reimbursement for LVN services was not incident to physician services, but to $85 \%$ of the physician reimbursement rate as per Section 1848 (p) of the Social Security Act. A second sensitivity analysis varied the expected impact of task shifting on potential treatment capacity, from no increase to a 3-fold increase.

\section{Results}

Driven by improved effectiveness and safety, $2^{\text {nd }}$ Gen DAAs treatment monitored by non-physician clinicians was projected to improve health outcomes, with a reduction of $71 \%$ for cases of decompensated cirrhosis, $63 \%$ for hepatocellular carcinoma, $71 \%$ for liver transplantation, and $68 \%$ for liver-related death, relative to $1^{\text {st }}$ Gen DAAs (Fig. 2). This trend was consistent across all subpopulations of patients (treatment-naïve, treatment-experienced, non-cirrhotic and cirrhotic) (Table 2), with the greatest relative improvements in health benefits seen in treatment-naïve non-cirrhotic patients and treatment-experienced non-cirrhotic patients where the treatments with $2^{\text {nd }}$ Gen DAAs showed the highest treatment effectiveness in our cohort (Fig. 1).

When a doubling of treatment capacity with task shifting with $2^{\text {nd }}$ Gen DAAs was assumed, on-treatment monitoring costs were reduced by $55 \%$ and total lifetime costs by $20 \%$ as compared with $1^{\text {st }}$ Gen DAAs (Table 3 ). The $2^{\text {nd }}$ Gen DAAs treatment monitored by non-physician clinicians was a dominant strategy (i.e. resulted in higher effectiveness in terms of life-years and quality-adjusted life years gained and lower total costs), relative to $1^{\text {st }}$ Gen DAAs. These trends were consistent across treatment-naïve, treatment-experienced, noncirrhotic and cirrhotic patient subpopulations. Across all patient subpopulations, $2^{\text {nd }}$ Gen DAAs within a task-shifted treatment model remained the dominant treatment strategy from a cost-effectiveness perspective.

Results from the first sensitivity analysis were similar to the base case (Table 4 ), with reductions of $56 \%$ in monitoring costs and $20 \%$ in total costs, relative to $1^{\text {st }}$ Gen DAAs, indicating that the analysis was not sensitive to small variations in provider reimbursement rates.

Our second sensitivity analysis varied expected increases in treatment capacity, from no increase to a 3 -fold increase (Table 5). With a 3-fold increase in treatment capacity enabled by task shifting, relative to the base case where a 2 -fold increase was assumed, advanced liver disease complications were projected to be even further reduced. Across all scenarios, task shifting remained a dominant strategy from a costeffectiveness perspective. 


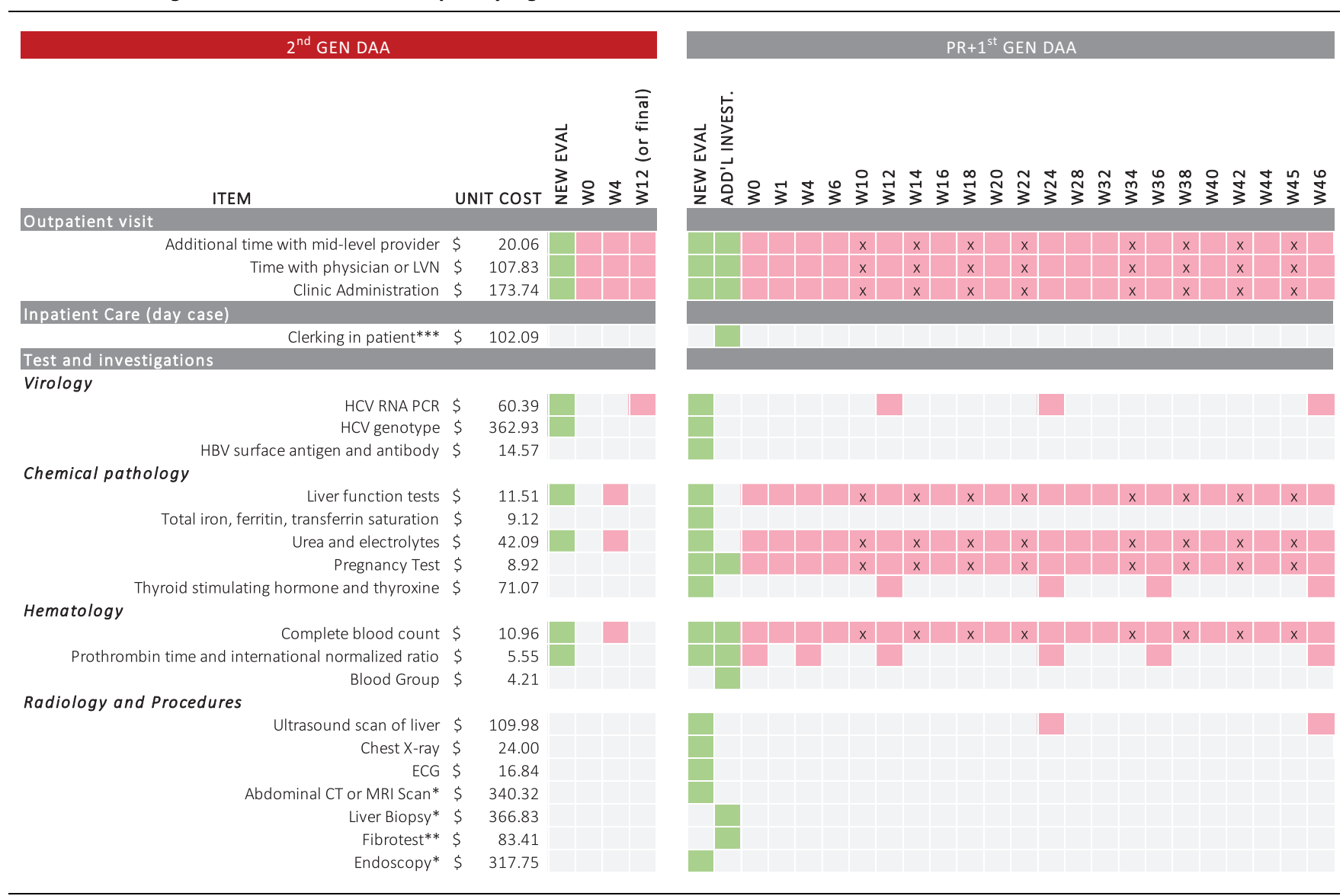

Green: initial assessment; Red: follow-up assessment. $* 20 \%$ of patients; $* * 80 \%$ of patients; $* * * 50 \%$ of patients; $x$, in cirrhotic patients only.

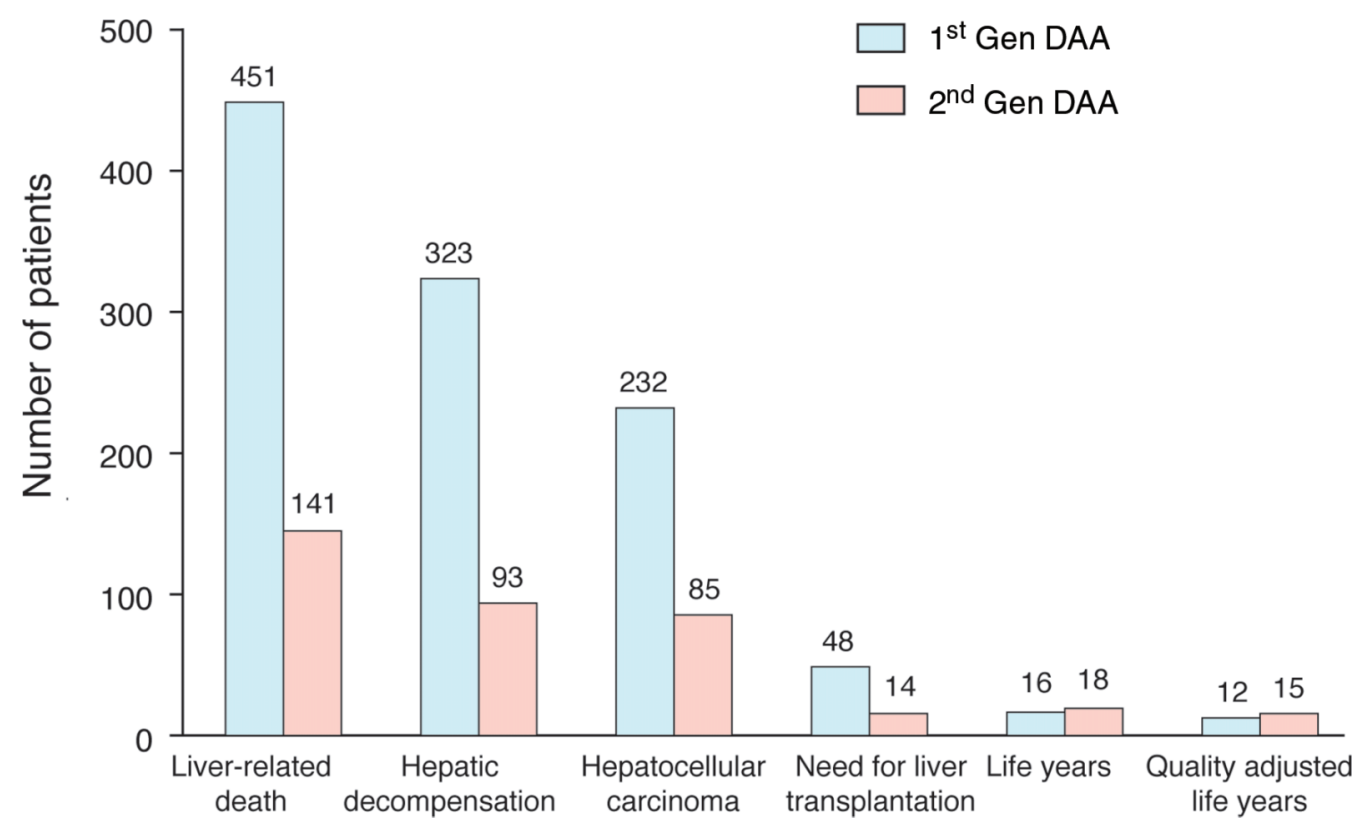

Fig. 2. Model results: health outcomes. $1^{\text {st }}$ Gen DAA, first generation direct-acting antiviral agents; $2^{\text {nd }}$ Gen $D A A$, second generation direct-acting antiviral agents. Analysis only includes patients with hepatitis $C$ genotype 1 . 
Jayasekera C.R. et al: Cost-effectiveness of task-shifted HCV care

Table 2. Health outcomes by patient subpopulation (per 10,000 patients)

\begin{tabular}{|c|c|c|c|c|c|c|c|c|}
\hline \multirow[b]{2}{*}{ Cases of: } & \multicolumn{2}{|c|}{$\begin{array}{l}\text { Treatment naïve } \\
\text { non-cirrhotic }\end{array}$} & \multicolumn{2}{|c|}{$\begin{array}{l}\text { Treatment naïve } \\
\text { cirrhotic }\end{array}$} & \multicolumn{2}{|c|}{$\begin{array}{l}\text { Treatment } \\
\text { experienced } \\
\text { non-cirrhotic }\end{array}$} & \multicolumn{2}{|c|}{$\begin{array}{l}\text { Treatment experienced } \\
\text { cirrhotic }\end{array}$} \\
\hline & $\begin{array}{l}2^{\text {nd }} \\
\text { Gen } \\
\text { DAA }\end{array}$ & $\begin{array}{l}1^{\text {st }} \text { Gen DAA } \\
+ \text { not } \\
\text { treated }\end{array}$ & $\begin{array}{l}2^{\text {nd }} \text { Gen } \\
\text { DAA }\end{array}$ & $\begin{array}{l}1^{\text {st }} \text { Gen DAA } \\
+ \text { not } \\
\text { treated }\end{array}$ & $\begin{array}{l}2^{\text {nd }} \\
\text { Gen } \\
\text { DAA }\end{array}$ & $\begin{array}{l}1^{\text {st }} \text { Gen DAA } \\
+ \text { not } \\
\text { treated }\end{array}$ & $\begin{array}{l}2^{\text {nd }} \text { Gen } \\
\text { DAA }\end{array}$ & $\begin{array}{l}1^{\text {st }} \text { Gen DAA } \\
+ \text { not } \\
\text { treated }\end{array}$ \\
\hline $\begin{array}{l}\text { Hepatic } \\
\text { decompensation }\end{array}$ & - & $1,990.8$ & $1,533.9$ & $3,883.7$ & 326.9 & $2,211.4$ & $1,444.0$ & $4,143.4$ \\
\hline $\begin{array}{l}\text { Hepatocellular } \\
\text { carcinoma }\end{array}$ & 23.7 & $1,493.3$ & $1,397.7$ & $2,771.4$ & 264.6 & $1,656.2$ & $1,345.2$ & $2,923.2$ \\
\hline $\begin{array}{l}\text { Liver } \\
\text { transplantation }\end{array}$ & - & 273.9 & 229.4 & 592.5 & 44.2 & 304.2 & 215.8 & 632.6 \\
\hline $\begin{array}{l}\text { Liver-related } \\
\text { death }\end{array}$ & 20.5 & $2,718.6$ & $2,417.4$ & $5,506.9$ & 456.4 & $3,017.4$ & $2,302.3$ & $5,847.9$ \\
\hline Life years & 19.5 & 17.9 & 17.3 & 14.6 & 19.2 & 17.7 & 17.4 & 14.3 \\
\hline $\begin{array}{l}\text { Quality adjusted } \\
\text { life years }\end{array}$ & 16.2 & 14.1 & 13.8 & 11.0 & 16.0 & 13.9 & 13.9 & 10.6 \\
\hline
\end{tabular}

$1^{\text {st }}$ Gen DAA, first generation direct-acting antiviral agents; $2^{\text {nd }}$ Gen DAA, second generation direct-acting antiviral agents. Analysis only includes patients with hepatitis $C$ genotype 1 . Results are presented per 10,000 patients.

\begin{tabular}{|c|c|c|c|c|}
\hline & \multirow{2}{*}{$\begin{array}{l}\text { Intervention } \\
2^{\text {nd }} \text { Gen DAA } \\
n=1000\end{array}$} & \multicolumn{3}{|l|}{ Comparator } \\
\hline & & $\begin{array}{l}1^{\text {st }} \text { Gen DAA }+ \text { not treated } \\
n=500+500\end{array}$ & $\begin{array}{l}1^{\text {st }} \text { Gen DAA } \\
\mathrm{n}=1000\end{array}$ & $\begin{array}{l}\text { Not treated } \\
\mathrm{n}=1000\end{array}$ \\
\hline Per patient total treatment cost ${ }^{*}$ & $\$ 131,398$ & $\$ 165,101$ & $\$ 170,305$ & $\$ 159,897$ \\
\hline Cost per SVR12 & $\$ 117,331$ & N/A & $\$ 187,058$ & N/A \\
\hline Per patient monitoring cost & $\$ 944.75$ & $\$ 2,116$ & $\$ 4,232$ & $\$ 0$ \\
\hline Total budget impact (mn) & $\$ 131.4$ & $\$ 165.1$ & N/A & N/A \\
\hline ICER & Dominant & Referent & N/A & N/A \\
\hline
\end{tabular}

* Product prices reflect wholesale acquisition cost and physician reimbursement costs are per the United States Centers for Medicare and Medicaid Services fee schedule. Abbreviations: SVR12, sustained viral response 12 weeks after end of treatment; mn, million; ICER, incremental cost-effectiveness ratio.

\begin{tabular}{|c|c|c|c|c|}
\hline & \multirow{2}{*}{$\begin{array}{l}\text { Intervention } \\
2^{\text {nd }} \text { Gen DAA } \\
n=1000\end{array}$} & \multicolumn{3}{|l|}{ Comparator } \\
\hline & & $\begin{array}{l}1^{\text {st }} \text { Gen DAA + not treated } \\
n=500+500\end{array}$ & $\begin{array}{l}1^{\text {st }} \text { Gen DAA } \\
\mathrm{n}=1000\end{array}$ & $\begin{array}{l}\text { Not treated } \\
n=1000\end{array}$ \\
\hline Per patient total treatment cost & $\$ 131,321$ & $\$ 165,069$ & $\$ 170,241$ & $\$ 159,897$ \\
\hline Cost per SVR12 & $\$ 117,306$ & $\mathrm{~N} / \mathrm{A}$ & $\$ 186,867$ & N/A \\
\hline Per patient monitoring cost & $\$ 935.33$ & $\$ 2,102$ & $\$ 4,204$ & $\$ 0$ \\
\hline Total budget impact (mn) & $\$ 131.3$ & $\$ 165.1$ & N/A & N/A \\
\hline ICER & Dominant & Referent & $\mathrm{N} / \mathrm{A}$ & $\mathrm{N} / \mathrm{A}$ \\
\hline
\end{tabular}

Abbreviations: SVR12, sustained viral response 12 weeks after end of treatment; mn, million; ICER, incremental cost-effectiveness ratio.

\section{Discussion}

Task shifting is widely used to manage chronic conditions including, most notably, HIV infection in areas where healthcare human resources are limited. The safety and effectiveness of task shifting in HIV treatment, and its ability to facilitate increases in treatment capacity, despite lifelong treatment durations and more complex and adverse effect-prone regimens than $2^{\text {nd }}$ Gen DAAs therapy, was demonstrated in several large studies and two subsequent Cochrane Database 


\begin{tabular}{llll}
\hline & $\begin{array}{l}\text { No increase in } \\
\text { treatment capacity }\end{array}$ & $\begin{array}{l}\text { Base case } \\
\text { (2-fold increase) }\end{array}$ & $\begin{array}{l}\text { 3-fold increase in } \\
\text { treatment capacity }\end{array}$ \\
\hline Patients treated with $\mathbf{2}^{\text {nd }}$ Gen DAA & 500 & 1000 & 1500 \\
Decompensated cirrhosis & -75.20 & -230.06 & -384.92 \\
Hepatocellular carcinoma & -47.94 & -147.47 & -247.00 \\
Liver transplantation & -11.04 & -34.13 & -57.21 \\
HCV-related death & -98.76 & -305.98 & -513.19 \\
Life years & 0.08 & 0.24 & 0.40 \\
Quality adjusted life years & 0.09 & 0.27 & 0.45 \\
Cost per SVR & $\$(34,863.64)$ & $\$ 23,801.66$ & $\$ 82,466.96$ \\
Total costs & $\$(19,453.34)$ & $\$(33,702.56)$ & $\$(47,951.78)$ \\
Monitoring costs & $\$(1,643.42)$ & $\$(1,171.05)$ & $\$(698.67)$ \\
Budget impact & $\$(19,453,335.52)$ & $\$(33,702,556.39)$ & $\$(47,951,777.27)$ \\
\hline
\end{tabular}

Results are represented as the difference between the current scenario ( 500 patients treated with $1^{\text {st }}$ Gen DAA) and the comparative scenarios (increased treatment capacity with $2^{\text {nd }}$ Gen DAA).

meta-analyses. ${ }^{17,19,20}$ Based on the success of HIV therapy in such settings, and the safety, effectiveness, and simplicity of interferon-free $2^{\text {nd }}$ Gen DAAs regimens, task shifting has been proposed as a strategy to expand access to HCV treatment as well. ${ }^{13,21}$ We previously demonstrated that, in medically underserved areas, $2^{\text {nd }}$ Gen DAAs-based HCV treatment can be administered effectively, despite devolving routine ontreatment monitoring to a non-physician clinician with very limited direct involvement of specialist physicians. In our experience, the treatment-related adverse events were no different from those at an academic medical center, and the availability of an on-call hepatologist to supervise nonphysician clinicians served as a means to minimize patient risk. ${ }^{14}$ Scaling-up task shifting in HCV, however, mandates demonstrating favorable cost effectiveness and budgetary impact of $2^{\text {nd }}$ Gen DAAs as compared with traditional interferon-based $1^{\text {st }}$ Gen DAA regimens within these task-shifted treatment models. In this analysis using a previously validated decision analytic Markov model, we evaluated the real-world budgetary impact and cost effectiveness of $2^{\text {nd }}$ Gen DAAs compared to $1^{\text {st }}$ Gen DAAs within a task-shifted treatment model, and across scenarios of increased treatment capacity.

Given our experiences in scaling up of HCV therapy while simultaneously being able to scale back the direct involvement of the hepatologist during routine treatment monitoring, we assumed that $2^{\text {nd }}$ Gen DAA regimens could double treatment capacity. Based on this assumption, we demonstrate that $2^{\text {nd }}$ Gen DAAs-based treatment is cost effective and cost saving as compared to $1^{\text {st }}$ Gen DAAs-based treatment, and these benefits extend to patient populations of treatmentnaïve non-cirrhotics, treatment-experienced non-cirrhotics, treatment-naïve cirrhotics, and treatment-experienced cirrhotics (Table 2). The magnitude of projected relative cost savings was smallest for the treatment-naïve cirrhotics, as this subpopulation had the smallest relative difference in SVR rate with $2^{\text {nd }}$ Gen DAA regimens versus $1^{\text {st }}$ Gen DAA regimens (Fig. 1). Even with an assumption of tripling treatment capacity, the $2^{\text {nd }}$ Gen DAA regimens remained cost effective and cost saving (Table 5). While cost effectiveness of $2^{\text {nd }}$ Gen DAA regimens versus $1^{\text {st }}$ Gen DAA regimens or no treatment has been previously demonstrated, and are reconfirmed here, our analysis represents the first, to our knowledge, that demonstrates the extension of these benefits when treatment capacity is expanded through workforce multiplication strategies such as task shifting. ${ }^{6-8}$

A key benefit of task shifting is the lower reimbursement rates of non-physician clinicians as compared to specialist physicians. Reduced reimbursement rates of non-physician clinicians, however, did not appear to contribute significant cost savings in our analysis; rather, the main driver was cost offsets from the avoidance of downstream advanced liver disease complications. This is unsurprising when the costs of $2^{\text {nd }}$ Gen DAA regimens and advanced liver disease events are considered. However, with increased marketplace competition among DAA regimens and anticipated shorter treatment durations, it can be envisaged that direct drug cost will decline further and provider reimbursement rates will proportionately be a larger component of the total cost of treatment.

Our model is limited by not accounting for differential reimbursement rates for services administered to patients covered under different types of insurers (i.e. commercial vs. Medicare vs. Medicaid) since all costs were sourced from Medicare databases. Given that patients in underserved areas of the United States are most likely to be insured by Medicaid, with lower reimbursement rates, the overall budget impact could be expected to be even lower than projected in this analysis. Secondly, $2^{\text {nd }}$ Gen DAAs and $1^{\text {st }}$ Gen DAAs were modeled as a class; differences in efficacy and cost between distinct all-oral $2^{\text {nd }}$ Gen DAA regimens (e.g. elbasvir+grazoprevir, LDV+SOF, ombitasvir+paritaprevir+ritonavir and dasabuvir, or SOF+SMV) and $1^{\text {st }}$ Gen DAA regimens (e.g. boceprevir+PR, simeprevir+PR, or telaprevir+PR) were not taken into account. The potential impact of using $2^{\text {nd }}$ Gen DAA regimens with even shorter treatment duration and costs (e.g. LDV+SOF for 8 weeks in selected patients) was not accounted for. Our clinic's demographics are also not typical of the general HCV-infected population in the United States, which has lower rates of prior treatment experience and cirrhosis. ${ }^{22-24}$ These differences, however, are likely to underestimate the magnitude of our findings, given the anticipated lower SVR rates seen in patients with prior treatment experience and cirrhosis. Our analysis also relied on real-world 
SVR rates for $2^{\text {nd }}$ Gen DAA regimens obtained from a relatively small population, and results should be validated in larger, real-world cohort studies.

In conclusion, we demonstrate here the cost effectiveness and cost-saving potential of $2^{\text {nd }}$ Gen DAAs-based HCV treatment within the context of task shifting and expansion of treatment capacity. These findings support the consideration of $2^{\text {nd }}$ Gen DAAs within task-shifted treatment models a means of increasing access to HCV treatment where linkages to specialist-level care are weak.

\section{Acknowledgments}

This study was supported by an unrestricted grant from Gilead Sciences, Inc (Foster City, California, USA) to Maple Health Group LLC.

\section{Conflict of interest}

Dr. Beckerman and Smith are consultant to Gilead, Dr. Wong is advisory board membership of Gilead and received research grants from Gilead, Dr. Younossi is consultant of AbbVie, Bristol Myers Squibb, Gilead, Glaxo Smith Kline, and Intercept, Dr. Ahmed is advisory board membership of AbbVie, Gilead, Intercept, Janssen, and Shire, and received research grants from Gilead and Intercept. The others have no conflict of interest to declare.

\section{Author contributions}

Conceived the study ( $A A, C R J)$, obtained the funding ( $R B$, $A A, C R J)$, acquired the data ( $A A, C R J)$, developed the models (RB, NS), interpreted the data and drafted the manuscript $(\mathrm{CRJ}, \mathrm{RB}, \mathrm{AA})$, critically reviewed the data and contributed to writing of the manuscript (RBP, RJW, ZMY).

\section{References}

[1] Denniston MM, Jiles RB, Drobeniuc J, Klevens RM, Ward JW, McQuillan GM, et al. Chronic hepatitis $C$ virus infection in the United States, National Health And Nutrition Examination Survey 2003 to 2010. Ann Intern Med 2014;160: 293-300. doi: 10.7326/M13-1133.

[2] Chak E, Talal AH, Sherman KE, Schiff ER, Saab S. Hepatitis C virus infection in USA: an estimate of true prevalence. Liver Int 2011;31:1090-1101. doi: 10. 1111/j.1478-3231.2011.02494.x.

[3] Yehia BR, Schranz AJ, Umscheid CA, Lo Re V 3rd. The treatment cascade for chronic hepatitis $C$ virus infection in the United States: a systematic review and meta-analysis. PLoS One 2014;9:e101554. doi: 10.1371/journal.pone. 0101554.

[4] Reau N. HCV testing and linkage to care: Expanding access. Clin Liver Dis 2014;4:31-34. doi: 10.1002/cld.376.

[5] Smith BD, Morgan RL, Beckett GA, Falck-Ytter Y, Holtzman D, Teo CG, et al. Recommendations for the identification of chronic hepatitis $C$ virus infection among persons born during 1945-1965. MMWR Recomm Rep 2012;61:1-32.
[6] Najafzadeh M, Andersson K, Shrank WH, Krumme AA, Matlin OS, Brennan T, et al. Cost-effectiveness of novel regimens for the treatment of hepatitis $C$ virus. Ann Intern Med 2015;162:407-419. doi: 10.7326/M14-1152.

[7] Chhatwal J, Kanwal F, Roberts MS, Dunn MA. Cost-effectiveness and budget impact of hepatitis $C$ virus treatment with sofosbuvir and ledipasvir in the United States. Ann Intern Med 2015;162:397-406. doi: 10.7326/M14-1336.

[8] Younossi ZM, Park H, Saab S, Ahmed A, Dieterich D, Gordon SC. Costeffectiveness of all-oral ledipasvir/sofosbuvir regimens in patients with chronic hepatitis C virus genotype 1 infection. Aliment Pharmacol Ther 2015;41:544-563. doi: 10.1111/apt.13081.

[9] Younossi ZM, Singer ME, Mir HM, Henry L, Hunt S. Impact of interferon free regimens on clinical and cost outcomes for chronic hepatitis $C$ genotype 1 patients. J Hepatol 2014;60:530-537. doi: 10.1016/j.jhep.2013.11.009.

[10] Association of American Medical Colleges. 2014 Physician specialty data book. Available from: https://members.aamc.org/eweb/upload/Physician \%20Specialty\%20Databook\%202014.pdf, accessed November 2014.

[11] Viner K, Kuncio D, Newbern EC, Johnson CC. The continuum of hepatitis C testing and care. Hepatology 2015;61:783-789. doi: 10.1002/hep.27584.

[12] Chirikov VV, Shaya FT, Howell CD. Contextual analysis of determinants of late diagnosis of hepatitis $C$ virus infection in medicare patients. Hepatology 2015;62:68-78. doi: 10.1002/hep.27775.

[13] Jayasekera CR, Arora S, Ahmed A. Hepatitis C treatment delivery mandates optimizing available health care human resources: a case for task shifting. JAMA 2016;315:1947-1948. doi: 10.1001/jama.2016.1993.

[14] Jayasekera CR, Perumpail RB, Chao DT, Pham EA, Aggarwal A, Wong RJ, et al. Task-shifting: an approach to decentralized hepatitis $C$ treatment in medically underserved areas. Dig Dis Sci 2015;60:3552-3557. doi: 10. 1007/s10620-015-3911-6.

[15] Gold MR, Siegel JE, Russell LB, Weinstein MC. Cost-effectiveness in health and medicine. New York: Oxford University Press, 1996.

[16] Ioannou GN, Beste LA, Green PK. Similar effectiveness of boceprevir and telaprevir treatment regimens for hepatitis $C$ virus infection on the basis of a nationwide study of veterans. Clin Gastroenterol Hepatol 2014;12: 1371-1380. doi: 10.1016/j.cgh.2013.12.011.

[17] Callaghan M, Ford N, Schneider H. A systematic review of task- shifting for HIV treatment and care in Africa. Hum Resour Health 2010;8:8. doi: 10. 1186/1478-4491-8-8.

[18] American Association for the Study of Liver Diseases. HCV guidance: recommendations for testing, managing, and treating hepatitis C. 2016. Available from: http://www.hcvguidelines.org, accessed July 6, 2016.

[19] Kredo T, Ford N, Adeniyi FB, Garner P. Decentralising HIV treatment in lowerand middle-income countries. Cochrane Database Syst Rev 2013;6: CD009987. doi: 10.1002/14651858.CD009987.pub2.

[20] Kredo T, Adeniyi FB, Bateganya M, Pienaar ED. Task shifting from doctors to non-doctors for initiation and maintenance of antiretroviral therapy. Cochrane Database Syst Rev 2014;7:CD007331. doi: 10.1002/14651858. CD007331.pub3.

[21] Ford N, Swan T, Beyer P, Hirnschall G, Easterbrook P, Wiktor S. Simplification of antiviral hepatitis $C$ virus therapy to support expanded access in resourcelimited settings. J Hepatol 2014;61:S132-S138. doi: 10.1016/j.jhep.2014. 09.019 .

[22] Gordon SC, Lamerato LE, Rupp LB, Holmberg SD, Moorman AC, Spradling $\mathrm{PR}$, et al. Prevalence of cirrhosis in hepatitis $C$ patients in the Chronic Hepatitis Cohort Study (CHeCS): a retrospective and prospective observational study. Am J Gastroenterol 2015;110:1169-1177; quiz 1178. doi: 10. 1038/ajg.2015.203.

[23] Kanwal F, Hoang T, Kramer JR, Asch SM, Goetz MB, Zeringue A, et al. Increasing prevalence of $\mathrm{HCC}$ and cirrhosis in patients with chronic hepatitis $\mathrm{C}$ virus infection. Gastroenterology 2011;140:1182-1188.e1. doi: 10.1053/j.gastro. 2010.12.032.

[24] Holmberg SD, Spradling PR, Moorman AC, Denniston MM. Hepatitis C in the United States. N Engl J Med 2013;368:1859-1861. doi: 10.1056/ NEJMp1302973. 